\title{
Motives and Manifestations of Sex as Self-Injury
}

Cecilia Fredlund, Marie Wadsby and Linda Jonsson

The self-archived postprint version of this journal article is available at Linköping University Institutional Repository (DiVA):

http://urn.kb.se/resolve?urn=urn:nbn:se:liu:diva-162515

N.B.: When citing this work, cite the original publication.

This is an electronic version of an article published in:

Fredlund, C., Wadsby, M., Jonsson, L., (2019), Motives and Manifestations of Sex as Self-Injury, Journal of Sex Research. https://doi.org/10.1080/00224499.2019.1689377

Original publication available at:

https://doi.org/10.1080/00224499.2019.1689377

Copyright: Taylor \& Francis (Routledge) (STM, Behavioural Science and Public Health Titles)

http://www.routledge.com/ 


\begin{abstract}
To view destructive sexual behaviors as a form of self-injury is a new concept in the research field that needs further exploration and conceptualization. The aim of this study was to explore experiences of sex as self-injury to identify motives and manifestations of the behavior. An anonymous self-selected open-ended questionnaire was used for the study, and qualitative content analysis was used to identify patterns and themes in the text. A total of 199 informants participated in the study $(M=27.9, S D=9.3$ years $)$, all of whom were recruited via a range of websites of Swedish nongovernmental organizations. Sex as selfinjury was described as voluntary exposure to sexual situations including psychological and/or physical harm. Affect regulation and receiving positive or negative confirmation emerged as important motives for the behavior. Respondents described sex as self-injury as difficult to stop when it felt compulsive and addictive, with ever-higher risk-taking and selfharming described. Our findings indicate that sex as self-injury often includes deliberate sexual violence, and is similar to other self-injurious behaviors, including non-suicidal selfinjury. Sex as self-injury needs to be addressed in healthcare, such as in psychiatry and gynecology departments, to prevent further traumatization.

Keywords: Sex as self-injury, Sexual risk-taking behavior, Sexual abuse, Revictimization
\end{abstract}




\section{Motives and Manifestations of Sex as Self-Injury}

In the last 15 years there has been a growing body of studies investigating non-suicidal self-injurious behaviors. The lifetime prevalence of non-suicidal self-injury (NSSI) in adolescents is high, at $17-18 \%$ of the general population. In clinical samples the prevalence is approximately $60 \%$ (Brown $\&$ Plener, 2017). Non-suicidal self-injury was included in the $5^{\text {th }}$ edition of the Diagnostic and Statistical Manual of Mental Disorders (DSM-5) from the American Psychiatric Association as a suggested diagnosis in need of more research. It was defined as self-inflicted damage to the surface of the body without suicidal intention and with motives such as relieving negative feelings, resolving interpersonal difficulties, or inducing positive feelings (American Psychiatric Association, 2013). The most common form of NSSI is cutting or burning the skin (International Society of the Study of Self-Injury [ISSS], 2018).

Sexual risk-taking behaviors are not usually included in the definition of NSSI, but are typically viewed as an indirect form of self-injury in which the self-injury is an unintended by-product (Muehlenkamp, 2005; Nock, 2010; St. Germain \& Hooley, 2012). However, recent studies from Sweden suggest that sexual behaviors could be used by adolescents to intentionally hurt themselves, and may share the same function as NSSI (Fredlund, Svedin, Priebe, Jonsson, \& Wadsby, 2017; Jonsson, Svedin, Priebe, Fredlund, Wadsby, \& Zetterqvist, 2019). The prevalence of sex as a means of self-injury (SASI) was investigated in a national Swedish school sample including 5750 participants with a mean age of 18 years. In total, $3.2 \%$ of the females and $0.8 \%$ of the males reported having intentionally hurt themselves by using sex on any occasion. Feeling pain during SASI was common and SASI was associated with earlier sexual abuse, especially penetrative sexual abuse, physical abuse, trauma symptoms and healthcare for depression, eating disorders and suicide attempts (Fredlund et al., 2017). The most common functions of the two behaviors were affect regulation, such as 'to relieve feeling numb or empty', 'to stop bad feelings', or 'to punish oneself'. Social 
functions such as 'to try to get a reaction from someone, even if it is a negative reaction' and 'to get attention' were more commonly reported among adolescents using SASI compared to adolescents using other forms of NSSI. Adolescents who reported both forms of self-injury (NSSI and SASI) reported more severe forms of self-injury and was also found to be more burdened and distressed group in regard of exposure of abuse, risk-taking behaviors and psychosocial health (Jonsson et al., 2019; Zetterqvist, Svedin, Fredlund, Priebe, Wadsby, \& Jonsson, 2018).

Sexual relations that in some way result in negative consequences for an individual are behaviors described extensively in the literature, including sexually abusive relationships, sex addiction, promiscuity, and sexual risk-taking behaviors. In the literature on sexual abuse, associations with later sexual risk-taking behavior are well described, including greater number of sexual partners, a higher frequency of sexually transmitted infections, higher risk of teenage pregnancy and prostitution, an earlier age of sexual debut (Draucker \& Mazurczyk, 2013; Fergusson, Horwood, \& Lynskey, 1997; Hailes, Yu, Danese, \& Fazel 2019; Lalor \& McElvaney, 2010; Messman-More \& Long, 2003; Steel \& Herlitz, 2005). Emotional dysregulation could help to predict the number of lifetime sexual partners and the frequency of risky sex with strangers and revictimization after sexual abuse (MessmanMoore, Walsh, \& DiLillo, 2010). Emotional dysregulation is also an important motivational factor for NSSI (Dixon-Gordon, Tull, \& Gratz, 2014; Ford \& Gómez, 2015), and has been associated with sexual risk-taking behaviors after sexual abuse and connected to posttraumatic stress (Messman-Moore, Walsh, \& DiLillo, 2010; Miron \& Orcutt, 2014; Orcutt, Cooper \& Garcia, 2005; Weiss, Walsh, DiLillo, Messman-More, \& Gratz, 2019).

Sexual risk-taking behavior as a consequence of earlier sexual abuse has been described in at least 40 years. To understand how sexual abuse could affect sexual behaviors the old model of traumagenic dynamics can be used. That is a model developed by Finkelhor \& 
Browne (1985). It was based on the existing literature on sexual child abuse and was an attempt on conceptualization of risk-taking behaviors related to sexual abuse that could be used both in research and in treatment. This model includes traumatic sexualization, stigmatization, betrayal, and powerlessness as consequences of sexual abuse. Traumatic sexualization is described as compulsive sexual behavior, a negative attitude towards sexuality, sexual abusive behavior, confusion about sexual identity or sexual norms, and negative connotations in relation to sex. Stigmatization may lead to a sense of being different, drug and alcohol abuse and forms of self-destructive behaviors including suicide attempts. Betrayal has been suggested as a dynamic behind a number of reactions after sexual abuse, such as aversion to intimate relationships or an intense need to regain trust and security. Victims of sexual abuse might also feel powerlessness, leading to a need to be in control of the sexual abuse which could lead to reenacting their own abuse or becoming an offender. These dynamics might be important in the understanding of SASI but have not yet been investigated in studies.

Although more is known about the prevalence, background factors and functions of SASI from earlier population-based studies, at least in a Swedish context, narratives and descriptions from people with this experience are still lacking (Fredlund et al., 2017; Jonsson et al., 2019; Zetterqvist et al., 2018). To be able to frame SASI in an adequate way, we need to understand better the meaning given to SASI, the underlying motives and the dynamics. Such insights are critical to efforts to find suitable support and treatment for this group of people.

\section{The Current Study}

The aim of the study was to explore self-reported experiences of using sex as selfinjury to get a deeper understanding of the motives and manifestations of the behavior. Qualitative methods were used to explore these experiences in individuals own words. The 
aim was to frame the phenomenon of SASI by investigating the onset of SASI, motivation and context of use, and the range of manifestations SASI could take.

\section{Method}

\section{Participants}

Participants were recruited from advertisements posted on the websites of Swedish nongovernmental organizations (NGOs) offering help and support to women and young people. The Internet was used as a source for finding participants and collecting answers since it has been found to be suitable for use when dealing with sensitive topics, where informants are expected to express their thoughts more freely and the sample is expected to be more diverse compared to face-to-face interviews (Markham, 2011).

A total of 199 participants who reported experiences of SASI completed the questionnaire: 190 women, 4 men, and 4 with non-binary identification. One person did not answer the question concerning gender. The participants were aged 15-64, with a mean age of 27.9 years $(S D=9.3)$ and a median age of 27 years. A majority of participants $(82.9 \%)$ had their first experience of SASI during adolescence, between the ages of 12 and 19. The reminder indicated that they were younger than $12(4.0 \%)$ or older than $19(10.6 \%)$ at onset.

\section{Measure}

The survey was designed by the experimenters based on their review of the literature and framed in parts by Finkelhor and Browne (1985) traumagenic model. The survey began with introductory text with information on the inclusion criteria (i.e., 15 years of age or older and having experience of SASI), and confirming that participants were anonymous and could discontinue the study at any time. A definition of SASI was presented in the introduction of the questionnaire as: 'Repeatedly sought sexual situations that have caused you physical and/or mental harm and that have affected you in your life.' 
The questionnaire included twelve open-ended questions concerning the age and gender of the participant, coping strategies for negative feelings or events and experiences of help and support. To explore motives and manifestations of SASI, respondents were asked to describe their experiences of sex as self-injury, with seven follow-up questions concerning the experience of SASI, how it started, why it continued, and how it stopped, see Appendix. Respondents were also asked to describe a typical occasion and who the other person was. The question 'In what way did you have sex as self-injury?' was added to the questionnaire two weeks into the survey to obtain more details concerning manifestations of SASI. This question was answered by 138 of the 199 participants.

The questionnaire was tested in a pilot study including five informants in October 2016, which resulted in changes to the structure of the questionnaire from more open-ended questions to more precise follow-up questions at the request of the participants.

\section{Procedure}

The survey was available from December 2016 until April 2017 to all visitors to the 37 NGOs from all parts of Sweden that had consented to publish the link to the questionnaire on their websites. The organizations were chosen in view of earlier findings associating SASI with earlier adverse events such as sexual abuse, which is why the study group was expected to visit the websites of organizations working with vulnerable women and young people (Fredlund et al., 2017).

The age limit for participation was 15 years since consent from parents is not required when participants are over 15 years of age (The Ministry of Education and Cultural Affairs, 2003). The study was approved by the Regional Ethical Review Board of Linköping University, Sweden, ref. 2016/386-31. The study included an information letter with information about the study, contact information for the researchers and details about help 
and support if needed after answering the questionnaire. Consent for participation was given by filling in the questionnaire.

Web-based survey software procured by Linköping University called Artologik Survey and Report was used to collect the answers for the study (Artologik, 2018).

\section{Data Analysis}

To explore the data, content analyses were used to identify patterns and themes in the text following guidelines for qualitative data analysis (Patton, 2015). All material was first read through by the authors. The text material was read through again carefully word by word to identify relevant statements for answering the aims of the study. These sentences were coded into initial themes, while maintaining the integrity of text. This process was carried out separately by two of the authors and resulted in an initial coding template. The coding categories were then discussed and compared by two of the authors and ordered into more formally themes and subthemes. In the next step, illustrative quotations were identified that explain the coding into the themes and subthemes. These units were then read through again and discussed in a group to assess internal homogeneity, specifically how well the units fit together, and external heterogeneity, meaning to what extent the units fit into other patterns and themes. In the next step, the patterns and themes were analyzed in view of divergence, connecting patterns and themes to each other and trying to identify new categories. This procedure was completed in discussion between the authors until saturation of patterns and themes was achieved. The number of participants reporting the themes and selected patterns was calculated to give the reader a feeling of the recurrence of answers as seen in Table 1, the numbers are also cited in the text. The survey was carried out in Swedish, so all quotations and citations were translated into English by the authors with the support of professional translators.

\section{Results}




\section{Manifestations of Sex as Self-injury}

Three main themes were identified describing the manifestations of sex as self-injury; 1) psychological harm in sexual situations; 2) physical harm in sexual situations; and 3) Selfinflicted context.

Psychological harm in sexual situations was one important manifestation of SASI reported by $72.4 \%$ of the informants. An example would be voluntary sexual intercourse despite the inner feeling of not wanting such sexual situations where there was no sexual desire for, attraction to or sexual interest in the other person. "Have had intercourse with guys I actually did not want to be with and had sex when I did not want to with the aim of hurting myself." (Woman, 22 years old).

Other example included having sex with a male even though the person was attracted to females or having sex with someone they found disgusting. "The most typical was an older man, around 25-40 year when I was in my teens. I'm not attracted to men so it was extra good self-injury somehow and it is often easier to make older men hurt you." (Women 23 years old).

Another example was letting the other person do whatever they wanted to do with one's body even though the sexual situation was against the inner feeling of desire, agreeing to everything or not disagreeing to anything in opposition to one's inner feelings. Sexual situations were used a way to punish or humiliate oneself. "Someone looked at me e.g. in a bar, often older men. If they wanted to have sex they got it. It caused me anguish and I was loathed. Often in toilets or outdoors. Sometimes I got money. I always cried afterwards." (Woman, 33 years old).

Physical harm in sexual situations in SASI was described by $44.2 \%$ of the informant. It was described as an active search for sexual situations in which the person experienced sexual or physical violence. This motive included descriptions from respondents of having 
anal sex even though it hurt, engage in sexual interactions with an apparently abusive person or sexual situations where the person knew they would be exploited or physically hurt. These sexual situations could include physical abuse, violent sex, unprotected sex, fisting, strangling, burning, spitting, hitting or verbal abasement. In most of these situations the physical pain seemed to be a central feature, and pleasure in relation to the violence was in general not described. Few, only $6.5 \%$, described positive feelings such as getting a "kick" or a feeling of being high during SASI. Rather, the sexual violence appeared to serve other functions, such as means of self-injury.

I have chosen to be submissive in sexual relationships, and in that way older men have violated me. Humiliated me, spat at me, spanked me and beaten me. Told me how little and worthless I am, told me that I am not worth more than to be a fuck doll. In this way I did not need to injure myself directly, instead have I self-injured indirectly. Over the years have I slept with about 50 men who have abused me through sex. (Woman, 27 years old).

Some informants described situations that they called 'self-elected rape' where the person herself could encourage or allow the sex partner to hit her or rape her. Informants described entering situations in which she knew she would be raped. The situations described were sometimes risky and even life-threatening, such as situations including severe strangling or a high risk of being violently raped. Some described fearing being kidnapped or killed. Some informants described apathy and feeling or believing that it did not matter what happened during the sexual encounter. Even though sexual and physical violence could be part of SASI, the exposure to SASI could result in risks of involuntary sexual violence, such as the other person using more violence than agreed, filming/photos, inviting other persons or using objects in the sexual act without consent. The informants described the difference between SASI and rape being that in SASI the situation was somehow voluntary, the person 
had some degree of control regarding their participation, and the sexual situation was somehow agreed to by the informant. In contrast, rape lacks control and includes lack of consent and violating what was agreed (if anything).

I have sought older men who want to dominate me, and I have let them do basically whatever they want with me. At the most it has been eight men at the same time. In most of the cases I have not been allowed to leave when I wanted to after I entered the door. The injuries have been many, both physical and mental. Despite this have I returned again. (Woman, 28 years old).

Self-inflicted context. Almost all informants (94.5\%) described the sexual situations in SASI as situations in which the informant had some kind of option in finding or not leaving the situation, but the contexts could be very diverse. Making contact was in many cases described as a deliberate or an active search for sexual contact, such as through the Internet or dating sites, bars, parties or anywhere in the vicinity. However, the sexual contact could also be posting or selling sexual pictures over the Internet, selling sex, having sex with many different persons in the same evening or each day, having sex in a relationship without saying no despite not wanting sex, or having unprotected sex as a way of hurting oneself by taking risks in terms of contracting sexually transmitted infections. Some described meeting people for sexual contact without making any selection, and engaging in sex with anyone who came their way. "I sold sex on the Internet. Or took the first best person in the bar/tram/neighborhood. Even disgusting persons that I despised. I just had to.” (Woman, 32 years old).

Sex as self-injury was typically described as an interpersonal act, both online and offline. The majority $(67.3 \%)$ described the other person as a casual contact, but $13.6 \%$ described SASI as occurring in relationships. Sex as self-injury involved men of all ages and in some cases women. In total $44.7 \%$ described contact with older men (more than 10 years 
older) and the contact was often made through the Internet. However, most of the informants described SASI as taking place in a sexual relationship with another person, but as seen in Table $1,8 \%$ of the informants described SASI as sexual injury to themselves. This could be in the form of compulsive masturbation, injury to the genitals with sharp objects, or the person herself repeating earlier sexual abuse in some way, including physical harm and pain. On some occasions I contacted/sought/met men who could injure me or more or less repeat the sexual abuse I had been exposed to earlier. Very violent. I also sought destructive relationships. Sometimes I contacted men on the Internet, who wrote mean, awful things they wanted to force me to do. Anyhow, I usually injured myself by repeating sexual actions on my own that perpetrators had forced me to do earlier. It felt like it happened again. I cried, said no, dissociated, experienced that the perpetrator was there and so on, despite the fact that it was only me causing myself injury. Injured myself physically e.g. in the genitals. And mentally of course all the time. (Woman, 22 years old).

\section{Motives for Sex as Self-injury}

Three themes were identified related to motives for sex as self-injury. The motives were described as; 1) emotion regulation; 2) confirmation; and 3) could not stop.

Emotion regulation. Almost all informants (94.0\%) described poor mental health including anxiety, depression and self-contempt as underlying motives for SASI. Sex as selfinjury was perceived to be a way to control their anxiety and to stop negative feelings or thoughts. One woman wrote:

I felt very bad and worthless. Sought men (and women but mostly men) on the Internet and left my address. I did not know who they were, how old and so on but I did not care either, I just wanted to get rid of my anxiety, sorrow and shame. (Woman, 25 years old). 
Many reasons were provided to explain their poor mental health by the participants, such as destructive relationships, harassment at school, painful breakups with partners, and emotional or physical abuse in childhood. Sexual abuse was a recurrent reason mentioned for poor mental health and the start of SASI. Feelings of self-contempt, low self-esteem and hatred of the body as a result of earlier sexual abuse were found to be underlying reasons for SASI. In total, $48.2 \%$ described SASI as being related to earlier sexual abuse and SASI was used as a way to repeat and control memories or cope with negative feelings in relation to the body after sexual abuse. Some informants found it easier to be in a real abusive situation compared to having the memories or sensations in the body from earlier sexual abuse, because it gave them a feeling of control over the situation and it also took the focus away from psychological distress.

After I was raped I felt that my body did not belong to me anymore, it did not matter who touched me and it did not matter what was done with my body - because it was full of disgust, destroyed and not mine anymore. So I had sex many times with people, even though I did not feel sexual desire or like the person. I have never said anything if the sex was hurting or not comfortable, I have let them finish and be satisfied. (Woman, 22 years old).

Sex as self-injury was perceived to be effective with regard to regulating emotional response, such as reducing anxiety and negative feelings, especially when pain was included. Some informants described that it was easier to feel the physical pain compared to the psychological pain. The physical pain was used as a way to ease the mental pain and could give a feeling of either being more present in the situation or escaping mentally as seen in dissociation. Some described emotional emptiness and were using SASI as a way to feel something even if it was pain. "If I have sex I do not need to think of all the painful things. 
And if one has sex a bit too hard such as BDSM, it causes physical pain so one does not feel the mental pain." (Woman, 18 years old).

Some informants described sex as self-injury and non-suicidal self-injury as similar with regard to their emotional ability to provide regulation, such as decreasing anxiety and psychological pain. Some had stopped using NSSI and started to use SASI instead. Some had alternated between different destructive behaviors, such as eating disorders, drug and alcohol abuse. In total, $21.6 \%$ reported having replaced other forms of self-injury with SASI. Sex as self-injury was sometimes preferred as it was more invisible and it was also easy to find men willing to have physically violent sex and in this way it was convenient.

After my relationship had ended I realized it was so viciously painful inside. If I had been braver I probably would have cut myself. But I did not dare because then my mother would see. And I did not want for all the world that my mother would see. Sex was more convenient and it was not seen outwardly. (Woman, 20 years old).

Confirmation. Sex as self-injury was not only used for regulation of negative emotions, it was also a way to receive positive confirmation, which was described by $55.8 \%$ of the informants. These behaviors were described as a way to get attention, affection and validation. They gave confirmation for being needed, being special, and important. It was a way for some to feel good at something (sex) and a way to be wanted (at least for their body). Have had sex with more than 100 people in my search for confirmation and acceptance. All the time it was about a quick fix, simply like an addiction that made me more and more depressed. The consequences have been numerous instances of sexual abuse, rapes and brutal rapes that have not been reported [to the police]. At the same time, I allowed guys/men to physically abuse me during the sex. (Woman, 27 years old). 
For some it became an identity, e.g. for being a 'slut'. Other informants described seeking real love and affection through the sexual meetings. When asked what made SASI continue, one woman wrote: "The anxiety, the shame and the feeling of being so fucking useless, the longing for love and confirmation. To feel that someone wanted me even though it was just for the moment and that I was not worth being their girlfriend." (Woman, 40 years old).

Low self-esteem, low self-confidence, self-contempt and self-hatred were frequently described as factors associated with engaging in SASI. In total, 30.2\% described negative confirmation as an important factor for SASI by being treated according to the inner feelings of self-contempt. These behaviors comprised a way to confirm a poor self-image, and informants described not feeling that they were worth being treated in a better way. Sex as self-injury provided a way to confirm the disgust for oneself or feelings of being worthless. Some described it as being easier to feel hatred towards a perpetrator than hatred towards oneself.

I allowed everyone to exploit me. Had no control. Exposed myself to dangerous, risky situations where I allowed people to have sex with me, sometimes several at the same time, to injure myself in a destructive way. I was worth nothing and it was only when I had this verified (though assaults and exploitation) that I found peace. For a short while. I think I also felt it was easier to hate them than to hate myself for a while. (Woman, 27 years old).

Could not stop. One important reason for SASI to continue, even though it was a sexual behavior resulting in negative consequences for the person, was that it was hard to stop, as described by $51.2 \%$ of the informants. Most informants described the relief of negative feelings during the sexual encounter, but the painful feelings often returned even stronger afterwards, resulting in a vicious circle, as described by $35.7 \%$ of the informants. 
Sex as self-injury could increase feelings of shame, guilt and self-contempt, which made the behavior start all over again. Informants described how sometimes more violence and abasement were needed to stop the negative feelings, resulting in a vicious loop of greater risk-taking or more severe self-harming situations over time.

Actually it started a long time ago with [sexual] abuse when I was little, plus physical abuse. It has given me a fear of intimacy that still affects my life. But since I had pressure from those around me and from healthcare I was desperate for a self-harming behavior that was invisible or left no scars. And through the Internet I started to find guys, but it was not enough so I started to sell myself for more abasement. When I got paid I lost all the rights to my body and even the possibility to say no. As a further step in this I agreed to unprotected intercourse if there was a desire for this. I get still suicidal thoughts and anxiety today if someone just touches me. (Woman, 30 years old).

In total, $20.1 \%$ described SASI in terms of being compulsive and addictive by their own definition. The informants compared SASI to an addiction because it seemed effective regarding emotion regulation during the sexual encounter, the behavior could escalate over time, ever-higher levels were needed to get the same effects, and it was hard to stop. Some described sexual risk-taking behavior that was at first found to be exciting, but that became increasingly destructive over time, delaying the realization that it was self-harming. Alcohol or drugs were described as being used in relation to SASI by $26.1 \%$ to help cope with the experiences or as a facilitator for SASI. Poor knowledge about the behavior and a lack of help and support from family, friends and healthcare were further reasons for the behavior continuing. Because of shame, it was hard for informants to disclose it to others and it was difficult to stop engaging in it without help. 
It became compulsive and addictive. Even though I stopped other self-harming behaviors I continued with this. At first because I did not understand it was destructive, and later because I could not stop. I tried to write contracts with myself. Used all the strategies that I had used to e.g. stop cutting myself. But I could not resist. The shame also contributed. Even though I had therapy in recent years, I did not dare to disclose this. I was too ashamed. I was sure my therapist would hate me, think I was disgusting or throw me out if I disclosed it. (Woman, 22 years old).

\section{Discussion}

The aim of the current study was to contribute to a better understanding of motives and manifestations of sex as self-injury, in order to better frame the behavior and to help inform efforts to support those who engage in SASI and wish to stop.

Sex as self-injury was described by the informants as sexual behaviors that knowingly lead to physical or psychological harm and that could occur in a range of contexts. The behavior was used as a means of emotion regulation and often to obtain positive or negative confirmation about their worth. In recent years there has been a growing body of research in the field of self-injurious behaviors. A related construct, non-suicidal self-injury, has been included as a suggested diagnosis in need of more research in the fifth version of the Diagnostic and Statistical Manual of Mental Disorders (DSM-5) published by the American Psychiatric Association (American Psychiatric Association, 2013). The suggested diagnosis of NSSI in DSM-5 did not include sex as self-injury or sexual risk-taking behaviors. Sexual risk-taking behaviors are considered to be an indirect form of self-injury in which the selfinjury is an unintended by-product meaning that there is no direct intended injury of body tissue (Muehlenkamp, 2005; Nock, 2010; St. Germain \& Hooley, 2012).

However, the results from this study indicate that SASI seems to fulfil all the DSM-5 criteria for NSSI diagnosis, including a) being intentionally and repeatedly sought to induce 
injury directed to the body, b) relieving negative feelings or inducing positive feelings, c) being associated with negative feelings or thoughts, being preceded by preoccupation with the intended behavior that is hard to control and thinking of the self-injury frequently even though it is not acted upon, d) the behavior not being socially sanctioned, e) the behavior causing significant distress or interfering with other personal functioning, and f) the behavior not being explained by other mental or medical disorders (American Psychiatric Association, 2013). Further, the sexual situations described in SASI could include direct injury and pain, physical violence and sexual violence that was not related to pleasure but was rather described as a way to cope with negative feelings such as anxiety. Sex as self-injury was described as a way to induce positive feelings, these were often related to being seen, being needed and getting confirmation, and were not related to obtaining pleasure from the sexual violence. Hence, we suggest that this behavior should be viewed as a self-injurious behavior comparable to cutting or burning the skin, despite it occurring in a sexual context with individuals, using the sexual encounter to accomplish the self-injury.

Most of the informants had started to use SASI during adolescence when aged 12-19, indicating a behavior in need of being highlighted in settings working with adolescents' psychological or sexual health. Earlier research revealed that groups at risk of SASI are persons with non-heterosexual identification and those exposed to earlier sexual abuse (Fredlund et al., 2017), indicating the need for more research and interventions for these groups.

Sex as self-injury was described in this study to occur mostly with another person. The context could be very diverse such as selling sex, constantly having new sexual partners, or having sex with older or unattractive persons, violent persons, or casual contacts met through the Internet, in bars or other settings. Thus, the contexts were not particularly useful for identifying the behavior. For example, adolescents may sell sex for a range of reasons, some 
of which may be related to SASI, but there might also be other reasons for selling sex, such as a need for money or drugs (Fredlund, Dahlström, Svedin, Wadsby, Jonsson, \& Priebe, 2018). In this way, not everyone with a sexual risk-taking behavior could be considered to have SASI, but SASI could certainly constitute a form of sexual risk-taking behavior.

An important issue that arose from this exploratory study is how SASI could be differentiated from sexual abuse, which could be important not least in relation to legal processes. The results from this study show that the context in which SASI occurs could be similar to situations of sexual abuse, but the distinction described by the informants was that the person had some kind of control in SASI or that the situations were somehow intentional or agreed upon. With regard to this question, it has to be kept in mind that shame and selfblame are common after sexual abuse and informants might misconceive the experience of sexual abuse as something voluntary. Further, SASI must still be seen as a form of sexual violence in regard to the severe violence and injury it could cause. Involuntary sexual and physical violence were repeatedly described as occurring in relation to SASI due to heightened risk of these. This outcome could be problematic in legal terms, since the victim could be blamed for having played an active part in taking the initiative for the sexual situation. However, it could be suggested that offenders have a greater responsibility or guilt as they might take advantage of the vulnerable position of a person who is often suffering from poor mental health, which might even be visible on the body in the form of scars after NSSI, as seen in earlier studies (Fredlund et al., 2017). The assessment of SASI in court cases needs to be examined further in research.

This study supports our theory from earlier studies, that sexual abuse and other adverse events are important factors for having destructive sexual relationships, such as sex as selfinjury (Fredlund et al., 2017; Zetterqvist et al., 2018). The informants described feeling that they were in control when injured through SASI compared to the earlier experience of being 
victims of sexual abuse. This outcome could be compared to the traumagenic dynamic powerlessness, a common dynamic after sexual abuse, which could be an explanation for reenacting the abuse by trying to take control of the situation (Finkelhor \& Browne, 1985). The informants described that it was better to be in a real situation of sexual abuse (SASI) compared to having the memories of earlier sexual abuse. Hence, sexual abuse seems to be one important factor for SASI to start and seems to be the most important risk factor for having SASI and not NSSI (Zetterqvist et al., 2018). The feeling of the body being destroyed or being of no value has been described as an important reason for using the body for prostitution (Coy, 2009). Further, negative attitudes towards one's own sexuality and the body are common after sexual abuse (Finkelhor \& Browne, 1985). This was also described by the informants in this study as hatred or disgust to the own body, hence it is an important reason for using SASI that could be related to earlier sexual abuse.

A negative loop of greater levels of self-harm and risk-taking in sexual situations was described by many informants. Some described being severely injured, being raped, being in fear of kidnapping or even being afraid of getting killed during the sexual encounters. Some described SASI as addictive and compulsive, and that it was hard to stop the behavior. Research concerning sexual abuse shows conclusively that earlier sexual abuse increases the risk of revictimization (Lalor \& McElvaney, 2010; Messman-More \& Long, 2003). Sexual risk-taking behaviors including early onset of sexual intercourse, great number of sexual partners, high frequency of sexually transmitted infections, teenage pregnancy and prostitution are factors that have been associated with the increased risk of revictimization after sexual abuse (Fergusson, Horwood, \& Lynskey, 1997; Lalor \& McElvaney, 2010; Messman-More \& Long, 2003; Steel \& Herlitz, 2005). It has been suggested in the traumagenic dynamic that promiscuity and compulsive sexual behavior might be one reason for revictimization of sexual abuse as part of traumatic sexualization (Finkelhor \& Browne, 
1985). SASI might be seen as a form of sexualized behavior after sexual abuse that might increase the risk of revictimization. However, not everyone with SASI has been exposed to earlier sexual abuse (Fredlund et al., 2017).

This study indicates a behavior that really needs to be highlighted in healthcare and other settings working with youths, such as schools and NGOs, to be able to prevent further victimization and traumatization. Understanding the function of emotion regulation behind SASI would help us to provide better help, support, and treatment for the behavior in healthcare making it possible to leave or break the vicious circle.

\section{Study Limitations and Future Directions}

The study had a number of limitations that should be noted. Using an online survey and not face-to-face interviews made it impossible to ask follow-up questions. The responses we obtained might be shorter compared to those obtained in an interview situation. However, the sample used was large, with 199 informants, and saturation was reached thus follow-up questions might therefore not have been necessary. In relation to shame and self-blame after sexual abuse, informants might misconceive the experience of sexual abuse as something voluntary, which has to be considered in the description of SASI. Most of the NGOs that cooperated were women's shelters offering help and support to women and young people exposed to threats, ill-treatment or sexual abuse. This probably effected the study group to include mostly women with experience of earlier abuse. This study could not describe SASI in relation to men or people with non-binary identification since most of the informants were women. A key question 'In what way did you have sex as self-injury?' was added to the survey two weeks into the survey. This item was answered by 138 of the 199 informants, thus not the entire sample. However, the patterns and themes were found to be saturated, and so this limitation should not have affected the results of the study. A definition of SASI was included in the introduction to the survey which might have affected the way of framing the 
concept of SASI for the informants. The definition included in the introduction implied a repeated behavior including physical or mental harm and might have affected the description of the behavior. There is a risk of recall bias since the informants sometimes described a behavior that had taken place in the past. Finally, the data was self-reported in nature and the sample might reveal a selection bias. However, the survey was anonymous and advertised widely.

Future research is needed to further frame the concept of SASI, not only in Sweden but also in other countries to investigate if this is a concept that is valid also in other countries and cultures. Further, research is needed in regard of help and support for this group. A first step might be to investigate informants own experience of help and support and in a second step more clinical trials are needed to frame how SASI could be assessed in healthcare.

\section{Conclusion}

In conclusion, sex as self-injury could be seen as a form of sexual violence that is somehow deliberate or sought by the person, including physical and/or psychological harm with the motives of resolving negative feelings or inducing positive feelings. The context of SASI can be diverse but has a common feature of including psychological or physical harm and a function of emotional regulation comparable to non-suicidal self-injurious behaviors, such as cutting or burning the skin. Sex as self-injury could cause victimization and traumatization by exposure to sexual risk-taking situations. It is a behavior that should concern healthcare workers, but it also needs to be addressed in other sections of society, such as in work to prevent sexual abuse and in justice.

\section{References}

American Psychiatric Association (2013). Diagnostic and Statistical Manual of Mental Disorders (5 $5^{\text {th }}$ ed.). Washington, DC: Author.

Artologik. Retrieved 2018 December 2 from https://www.artologik.com/en/Start.aspx 
Brown, R. C., \& Plener, P. L. (2017). Non-suicidal self-injury in adolescence. Current Psychiatry Reports, 19:20. doi:10.1007/s11920-017-0767-9

Coy, M. (2009). This body which is not mine: The notion of the habit body, prostitution and (dis)embodiment. Feminist Theory, 10, 61-75. doi:10.1177/1464700108100392

Dixon-Gordon, K. L., Tull, M. T., \& Gratz, K. L. (2014). Self-injurious behaviors in posttraumatic stress disorder: An examination of potential moderators. Journal of Affective Disorders, 166, 359-367. doi:10.1016/j.jad.2014.05.033

Draucker, C. B., \& Mazurczyk, J. (2013). Relationships between childhood sexual abuse and substance use and sexual risk behaviors during adolescence: An integrative review. Nursing Outlook, 61, 291-310. doi:10.1016/j.outlook.2012.12.003

The Ministry of Education and Cultural Affairs (2003). The Act Concerning The Ethical Review Of Research Involving Humans (SFS 2003:460). Stockholm: The Swedish Ministry of Education and Cultural Affairs. https://www.onep.se/media/2348/the_ethical_review_act.pdf

Fergusson, D. M., Horwood L. J., \& Lynskey, M. T. (1997). Childhood sexual abuse, adolescent sexual behaviors and sexual revictimization. Child Abuse \& Neglect, 21, 789-803. doi: $10.1016 / \mathrm{S} 0145-2134(97) 00039-2$

Finkelhor, D. \& Browne, A. (1985). The traumatic impact of child sexual abuse: a conceptualization. The American Journal of Orthopsychiatry 55, 530-541. doi: 10.1111/j.1939-0025.1985.tb02703.x

Ford, J. D. \& Gómez, J. M. (2015). The relationship of psychological trauma and dissociative and posttraumatic stress disorder to nonsuicidal self-injury and suicidality: a review. Journal of Trauma \& Dissociation, 16, 232-271. doi:10.1080/15299732.2015.989563

Fredlund, C., Dahlström, Ö., Svedin, C. G., Wadsby, M., Jonsson, L. S., \& Priebe, G. (2018) Adolescents' motives for selling sex in a welfare state - A Swedish national study. Child Abuse and Neglect 81, 286-295. doi: 10.1016/j.chiabu.2018.04.030 
Fredlund, C., Svedin, C. G., Priebe, G., Jonsson, L. S., \& Wadsby, M. (2017). Self-reported frequency of sex as self-injury (SASI) in a national study of Swedish adolescents and association to sociodemographic factors, sexual behaviors, abuse and mental health. Journal of Child and Adolescent Mental Health, 11, article 9. doi:10.1186/s13034-017-0146-7

Hailes, H. P., Yu, R., Danese, A., \& Fazel, S. (2019). Long-term outcomes of childhood sexual abuse: an umbrella review. The Lancet Psychiatry, 6, 830-839. doi:10.1016/S22150366(19)30286-X

International Society for the Study of Self-Injury [ISSS] (2018). About self-injury. Retrieved 2018 November 22 from https://itriples.org/category/about-self-injury/.

Jonsson, L. S., Svedin, C. G., Priebe, G., Fredlund, C., Wadsby, M., \& Zetterqvist, M. (2019). Similarities and differences in the functions of nonsuicidal self-injury (NSSI) and sex as selfinjury (SASI). Suicide and Life-Threatening Behavior 49, 120-136. doi: 10.1111/sltb.12417

Lalor, K. \& McElvaney R. (2010). Child sexual abuse, link to later sexual exploitation/high-risk sexual behavior and prevention/treatment programs. Trauma, Violence and Abuse, 11, 159177. doi:10.1177/1524838010378299

Markham, A. N. (2011). Internet research. in Silverman D. (Ed.). Qualitative Research (3 ${ }^{\text {rd }}$ ed.) (pp. 111-127). London: SAGE Publications.

Messman-More, T. L., \& Long, P. J. (2003). The role of childhood sexual abuse sequelae in the sexual revictimization of women: An empirical review and theoretical reformation. Clinical Psychology Review, 23, 537-571. doi: 10.1016/S0272-7358(02)00203-9

Messman-Moore T. L., Walsh, K. L., \& DiLillo, D. (2010). Emotion dysregulation and risky sexual behavior in revictimization. Child Abuse \& Neglect, 34, 967-976. doi:10.1016/j.chiabu.2010.06.004 
Miron, L. R. \& Orcutt, H. K. (2014). Pathways from childhood abuse to prospective revictimization: Depression, sex to reduce negative affect, and forecasted sexual behavior. Child Abuse \& Neglect, 38, 1848-1859. doi:10.1016/j.chiabu.2014.10.004

Muehlenkamp, J. J. (2005). Self-injurious behavior as a separate clinical syndrome. American Journal of Orthopsychiatry, 75, 324-333. doi: 10.1037/0002-9432.75.2.324

Nock, M. K. (2010). Self-injury. Annual Review of Clinical Psychology, 6, 339-363. doi:10.1146/annurev.clinpsy.121208.131258

Orcutt, H. K., Cooper, M. L., \& Garcia, M. (2005). Use of sexual intercourse to reduce negative affect as a prospective mediator of sexual revictimization. Journal of Traumatic Stress, 18 , 729-739. doi:10.1002/jts.20081

Patton, M. Q. (2015). Qualitative Research \& Evaluation Methods. Thousand Oaks, CA: Sage Publications.

Steel, J. L. \& Herliz C. A. (2005). The association between childhood and adolescent sexual abuse and proxies for sexual risk behavior: A random sample of the general population of Sweden. Child Abuse \& Neglect, 29, 1141-1153. doi:10.1016/j.chiabu.2004.10.015

St. Germain, S. A. \& Hooley, J. M. (2012). Direct and indirect forms of non-suicidal self-injury: Evidence for a distinction. Psychiatry Research, 197, 78-84. doi:10.1016/j.psychres.2011.12.050

Weiss, N. H., Walsh, K., DiLillo, D. D., Messman-Moore, T. L., \& Gratz, K. L. (2019). A Longitudinal Examination of Posttraumatic Stress Disorder Symptoms and Risky Sexual Behavior: Evaluating Emotion Dysregulation Dimensions as Mediators. Archives of Sexual Behavior, 48, 975-986. doi:10.1007/s10508-019-1392-y

Zetterqvist M., Svedin, C. G., Fredlund, C., Priebe, G., Wadsby, M., \& Jonsson, L. S. (2018). Self-reported nonsuicidal self-injury (NSSI) and sex as self-injury (SASI): Relationship to 
abuse, risk behaviors, trauma symptoms, self-esteem and attachment. Psychiatry Research, 265, 309-316. doi: 10.1016/j.psychres.2018.05.013 
Table 1

Main findings for Motives and Manifestations of Sex as Self-Injury

\begin{tabular}{|c|c|c|}
\hline \multirow[b]{2}{*}{ Manifestations of SASI } & \multicolumn{2}{|c|}{$n=199$} \\
\hline & $n$ & $\%$ \\
\hline Psychological harm in sexual situations & 144 & 72.4 \\
\hline Physical harm in sexual situations & 88 & 44.2 \\
\hline Self-inflicted context & 188 & 94.5 \\
\hline Casual contact & 134 & 67.3 \\
\hline In a relationship & 27 & 13.6 \\
\hline Older men (more than 10 years older) & 89 & 44.7 \\
\hline Self-inflicted SASI (not interpersonal) & 16 & 8.0 \\
\hline \multicolumn{3}{|l|}{ Motives of SASI } \\
\hline Emotion regulation & 187 & 94.0 \\
\hline To replace other self-injury & 43 & 21.6 \\
\hline In relation to earlier sexual abuse & 96 & 48.2 \\
\hline Confirmation & 137 & 68.8 \\
\hline Positive confirmation & 111 & 55.8 \\
\hline Negative confirmation & 60 & 30.2 \\
\hline Could not stop & 102 & 51.2 \\
\hline Vicious circle/loop & 71 & 35.7 \\
\hline Compulsive or addictive & 40 & 20.1 \\
\hline
\end{tabular}




\section{Appendix}

The questions used for the survey Sex as Self-Injury, Motives, Manifestations and Support

1. How old are you?

2. What is your gender identity? E.g. woman, man, non-binary?

3. What do you usually do to cope with negative feelings or occurrences?

4. Describe your experiences of sex as self-injury

4a. In which way did you have sex as self-injury?

4b. How did it start?

4c. How old were you when you had sex as self-injury? Do you still have it?

4d. What made it continue?

4e. Describe a typical occasion when you had sex as self-injury, what happened?

4f. Think of a typical occasion. If this happened with another person, what

relationship did you have to the other person and what was his/her age and gender?

$4 \mathrm{~g}$. If you have stopped, what made you stop?

5. What experiences did you have of help and support when you had sex as selfinjury?

6. What did you wanted in regard of help, support and treatment from healthcare or other organizations working with help and support when you had sex as self-injury? 
Cecilia Fredlund ${ }^{a *}$, Marie Wadsby ${ }^{a}$, Linda S Jonsson ${ }^{b}$

${ }^{a}$ Child and Adolescent Psychiatry, Department of Clinical and Experimental Medicine, Faculty of Medicine, Linköping University,SE-58185Linköping,SwedenE-mail: cecilia.fredlund@liu.se, marie.wadsby@liu.se ${ }^{b}$ Barnafrid, Child and Adolescent Psychiatry, Department of Clinical and Experimental Medicine, Faculty of Medicine, Linköping University,SE-58183_Linköping, Sweden_E-mail:_linda.s.jonsson@liu.se

*Corresponding author cecilia.fredlund@liu.se,phone: +46733803063

\section{Acknowledgements}

We would like to thank Malin Jenstav and Malin Meissner at Stockholm Tjejjour for their cooperation and their help and support with the data collection. We would also like to acknowledge all the organizations that have shared our questionnaire on their websites or social media: Stockholms Tjejjour, Ungdomsjouren Animo, Örebro tjejjour, Tjejjouren Luleå, Tjejjouren Lund, Tjejjouren Norrköping, Tjejjouren Beate Linköping, Tjejjouren Miranda, Tjejjouren Lina, Lycksele Tjejjour, Tjejjouren Indra, Juventas Ungdomsjour, Uppsala Tjejjour, Trans- och Tjejjouren Malmö, Karlstad Tjejjour, Tjejjouren Lotus, Tjejjouren Meja, Tjejjouren Magnolia, Tjejjouren Ronja, Föreningen Storasystrar, Föreningen Tillsammans, RFSU, Tjejzonen, RISE, HOPP, WONSA, 1000 möjligheter, Sheedo, Föreningen Tilia, Roks, Unizon, tjejjouren.se, inte till salu, Kvinno- och tjejjouren Huddinge, Kristianstad kvinnojour, Kvinnohuset KG and umo.se. Finally, we would like to thank the participants in the study for sharing their stories. 